\title{
Prevalence of malaria in Woreta town, Amhara region, Northwest Ethiopia over eight years
}

\author{
Amir Alelign ${ }^{1,2^{*}}$, Zinaye Tekeste ${ }^{3}$ and Beyene Petros ${ }^{1}$
}

\begin{abstract}
Background: Data on trends in malaria prevalence is significant to assist efforts in the control and prevention of the disease. This retrospective study was, therefore, aimed to determine the prevalence of malaria in Woreta town, northwestern Ethiopia over 8 years.

Methods: A retrospective study was conducted in Woreta town, northwestern Ethiopia, from November to January 2013. Eight years (2005 to 2012) health center record of malaria cases was reviewed. Odds ratio (OR) was used to determine trend in malaria prevalence with respect to age, sex and Plasmodium species. $P$-values less than 0.05 were considered to be statistically significant.

Results: From 2005 to 2012, a total of 102,520 suspected cases of malaria were reported at Woreta health center. Of these, 33,431 (32.6\%) were microscopically confirmed to be positive for the disease. Among these positive cases, 17,700 (52.9\%) and 15,731 (47.1\%) were males and females, respectively. Children less than 5 years old were 1.3 times more likely to be infected by malaria than those with $5-15$ years ([OR]; 1.3, 95\% confidence interval [Cl]; 1.26-1.34, $p<0.001$ ). There was higher percentage (69.7\%) of Plasmodium falciparum infection than Plasmodium vivax (26.5\%); and the difference was statistically significant $(p<0.05)$. There was fluctuation in yearly malaria prevalence with a minimum of $7 \%$ in 2008 and maximum of $47 \%$ in 2005.

Conclusions: The present study revealed that malaria continued to be one of the major public health problems in Woreta town, northwest Ethiopia. Moreover, there was no successive yearly reduction in its prevalence. Therefore, efforts are required to reduce the disease burden through continuous monitoring and evaluation of control measures in the study area.
\end{abstract}

Keywords: Malaria, Prevalence, Retrospective, Woreta, Ethiopia

\section{Background}

Global malaria prevention and control have been scaled up in the past decade, with notable progress in sub-Saharan Africa. [1]. However, the transmission of the diseases remained active in many countries around the world. By the end of 2015, there were 95 countries and territories with ongoing malaria transmission. Globally, an estimated 214 million cases and 438,000 deaths occurred due to malaria in the same year. Most cases and deaths

\footnotetext{
* Correspondence: aleamiro2009@gmail.com

${ }^{1}$ Department of Microbial, Cellular and Molecular Biology, Addis Ababa University, P.O.Box 1176, Addis Ababa, Ethiopia

${ }^{2}$ Department of Biology, College of Computational and Natural Sciences, Debrebirhan University, Debrebirhan, Ethiopia

Full list of author information is available at the end of the article
}

were estimated to have occurred in the African region (88\%), followed by the South-East Asia region [2].

In Ethiopia, malaria remained to be the leading communicable disease seen at health facilities [3]. It accounted for up to $14 \%$ of outpatient consultations and $9 \%$ of health facility admissions. It has been estimated that there were 510 million clinical malaria cases and approximately 70,000 people die of it each year in the country [4].

Malaria has continued to be one of the major public health challenges in the Amhara region, where children and pregnant women were severely affected [5]. A total of $1,127,241$ cases of malaria were reported within the region in 2012. Out of eight zones in the region, only five of them accounted for $93.1 \%$ of the total malaria burden. South

(c) The Author(s). 2018 Open Access This article is distributed under the terms of the Creative Commons Attribution 4.0 International License (http://creativecommons.org/licenses/by/4.0/), which permits unrestricted use, distribution, and 
Gondar zone accounted for the third greatest number of cases in the region next to West Gojam and North Gondar zones. Malaria prevalence declined significantly in the Amhara region from $4.6 \%$ in 2006 to $0.6 \%$ in 2007 and $0.8 \%$ in 2011 [6].

In the Amhara region, prevention and control activities of the disease have been implemented as guided by the National Strategic Plan: A combination intervention strategy including early diagnosis and prompt treatment, selective vector control that involved use of indoor residual spraying (IRS), insecticide-treated mosquito nets (ITNs) and environmental management [7]. However, malaria control in the country as a whole and in the region particularly continued to experience many problems.

Studies have shown that the number of malaria cases and plasmodium species composition vary over time. This variation was suggested to be due to climatic, intervention measures, environmental or human behavioral risk factors in those years [8-12].

Assessment of the pattern of malaria burden in the past years and comparing it to the present will help to evaluate the effectiveness of proven control interventions of the disease in a locality [12]. However, much work has not been done to this extent in malaria endemic regions of Ethiopia such as Woreta. Therefore, the present study aimed to assess the prevalence of malaria in person and Plasmodium species composition in the past 8 years (2005-2012) in Woreta.

\section{Methods}

\section{Study area}

The study was conducted at Woreta town, Fogera district, Amhara region, northwest Ethiopia. The area is located $625 \mathrm{~km}$ north of Addis Ababa (the capital of Ethiopia). The district has been divided in to 30 rural and 5 urban 'kebeles' (the smallest administrative unit) in the district and Woreta and Alember were the major towns. The total human population of the district was 233,529 , of which, 26,812 was urban population. Fogera has been known for its flat and low land. The district has been regarded as malarious. The altitude of the district ranged between 1750 and $2100 \mathrm{~m}$ above sea level. The capital of the district, Woreta town, had an altitude and longitude of $11^{\circ} 55^{\prime} \mathrm{N} 37^{\circ} 42^{\prime} \mathrm{E}$ with an elevation of $1828 \mathrm{~m}$ above sea level. Mean annual precipitation was $1225.8 \mathrm{~mm}$ with mean maximum and minimum temperatures of 27.9 and $12.6^{\circ} \mathrm{C}$. The major portion of the total annual rain fall was received between June and October [13]. Malaria has been the most prevalent seasonal disease in the area, and October to December was the peak transmission season.

\section{Study design and population}

A retrospective study was conducted to determine prevalence of malaria in Woreta town over 8 years (2005-2012).
The town has been divided in to four 'kebeles'. The study population included residents of the four 'Kebeles' in the town who had visited the health center during the study period and suspected of malaria.

\section{Data collection}

An 8 years (2005-2012) retrospective data on malaria prevalence was collected from May to July 2013 at Woreta health center. In this health center, peripheral smear examination of blood film has been used as the gold standard in confirming the presence of malaria infection.

\section{Data quality control}

The retrospective data were taken from the primary record book of the health center. The information of every member of the community was registered during their visit to the health center within the study period. Three trained health workers collected the data independently and cross cheeked each other and finally confirmed by the first author.

\section{Data analysis}

The data were entered in Microsoft Excel data sheets, cross checked and transferred, and analyzed using SPSS 16 software package. Odds ratio (OR) with the corresponding 95\% confidence interval (CI) was used to determine the differences in malaria prevalence and Plasmodium species distribution among the different age groups and sexes over time. $P$-values $<0.05$ were considered to be statistically significant.

\section{Results}

A total of 102,520 blood films were examined for malaria from 2005 to 2012 at Woreta health center. Of these, 33,431 [17,700 (52.9\%) males and 15,731 (47.1\%) females] were positive for malaria (Table 1). About 52.6, 23.5 and $23.9 \%$ of individuals in the $>15,<5$ and from 5 to 15 years age groups were malaria infected, respectively. Totally, malaria infection in children $<5$ years was significantly lower than that of individuals with 5 to 15 and $>15$ years age groups $[(<5$ years vs. $5-15$ years, OR: 1.30 , CI: $1.26-$ $1.34, p<0.05)((<5$ years vs. $>15$ years, OR: $1.29, \mathrm{CI}$ : $1.24-1.33, p<0.05)$ ] (Table 1).

Of the total malaria cases identified, there was significantly higher P.falciparum (69.7\%) infection than P.vivax $(26.5 \%) \quad(p<0.05)$. Mixed infection accounted only for $3.8 \%$ of the total cases. Higher percentage of P.falciparum infection was recorded in all age groups and in both sexes. Totally, infections by $P$. falciparum and P.vivax malaria were about 2.7 (OR: 2.66 ; CI: $2.46-2.89 ; p<0.001$ ) and 3.0 (OR: 2.99; CI: $2.76-3.26 ; p<0.001)$ times more likely to occur than mixed (both $P$. falciparum and $P$. vivax) infections, respectively (Table 2). 
Table 1 Distribution of malaria cases by sex and age, Woreta town, Northwest Ethiopia. (2005-2012)

\begin{tabular}{|c|c|c|c|c|c|}
\hline \multicolumn{6}{|c|}{ Malaria cases } \\
\hline Sex & Age groups (years) & Positive (\%) & Negative(\%) & OR $(95 \% \mathrm{Cl})$ & $p$-value \\
\hline \multirow[t]{4}{*}{ Males } & $<5$ & 3304 (18.7) & $8075(23.4)$ & 1.00 & \\
\hline & $5-15$ & $10,027(56.6)$ & $17,995(52.1)$ & $1.36(1.30-1.40)$ & $<0.001$ \\
\hline & $>15$ & $4369(24.7)$ & $8449(24.5)$ & $1.26(1.20-1.34)$ & $<0.001$ \\
\hline & Sub- total & $17,700(100.0)$ & $34,519(100.0)$ & & \\
\hline \multirow[t]{4}{*}{ Females } & $<5$ & $4558(29.0)$ & $11,658(33.9)$ & 1.00 & \\
\hline & $5-15$ & $7565(48.1)$ & $15,656(45.5)$ & $1.24(1.18-1.30)$ & $<0.001$ \\
\hline & $>15$ & $3608(22.9)$ & 7085 (20.6) & $1.30(1.24-1.40)$ & $<0.001$ \\
\hline & Sub- total & $15,731(100.0)$ & $34,401(100.0)$ & & \\
\hline \multirow[t]{4}{*}{ Total } & $<5$ & $7862(23.5)$ & $19,639(28.4)$ & 1.00 & \\
\hline & $5-15$ & $17,592(52.6)$ & $33,912(49.1)$ & $1.30(1.26-1.34)$ & $<0.001$ \\
\hline & $>15$ & 7977 (23.9) & $15,538(22.5)$ & $1.29(1.24-1.33)$ & $<0.001$ \\
\hline & Total & $33,431(100.0)$ & $69,089(100.0)$ & & \\
\hline
\end{tabular}

$\mathrm{Cl}$ confidence interval, OR odds ratio; $<5$ and $<15$ indicated study subjects who were less than 5 and 15 years of ages in both sexes, respectively; $>15$ indicated those study subjects who were above 15 years of ages

A fluctuating trend was observed in the yearly malaria prevalence. It was observed to range from $7 \%$ in 2008 to $43 \%$ in 2005 . There were peaks in the prevalence in 2005 and 2010 (Fig. 1). There was a sharp increase of malaria prevalence from 2008 to 2010 and a fall from 2010 to 2011.

Of the total malaria positive cases in 2005 , about 77 (87\%) and $9(10 \%)$ were due to $P$. falciparum and $P$. vivax, respectively (Fig. 2). From 2009 to 2012, the prevalence of $P$. falciparum showed a decreasing pattern but that of $P$. vivax reflected a slight increment $(18 \%$ in $2009,28 \%$ in $2010,31 \%$ in 2011 and 33\% in 2012). The highest prevalence of mixed infection (6\%) was observed in 2007 (Fig. 2).

There were two peaks of malaria season in the study area; one was in Autumn (March to May), and the other was in Spring (September to November). The highest (4100) and lowest (800) average cases of malaria were recorded during Spring and Winter (December to February), respectively (Fig. 3).

Table 2 Distribution of malaria cases by age groups and species, Woreta town, northwest Ethiopia (2005-2012)

\begin{tabular}{|c|c|c|c|c|c|}
\hline \multicolumn{6}{|l|}{ Malaria cases } \\
\hline Age groups & Diagnosis & Positive (\%) & Negative (\%) & OR $(95 \% \mathrm{Cl})$ & $p$-value \\
\hline \multirow[t]{4}{*}{$<5$} & P.falciparum & $5097(64.8)$ & $18,901(71.4)$ & $7.04(2.46-2.89)$ & $<0.001$ \\
\hline & P.vivax & 2501 (31.8) & $7432(28.1)$ & $5.64(4.57-6.96)$ & $<0.001$ \\
\hline & Mixed & $264(3.4)$ & $139(0.5)$ & 1.00 & \\
\hline & Sub-total & $7862(100.0)$ & $26,472(100.0)$ & & \\
\hline \multirow[t]{4}{*}{$5-15$} & P.falciparum & $12,194(69.3)$ & $26,065(67.7)$ & $2.32(2.08-2.59)$ & $<0.001$ \\
\hline & P.vivax & $4694(26.7)$ & $11,788(30.6)$ & $2.73(2.44-3.05)$ & $<0.001$ \\
\hline & Mixed & $704(4.0)$ & $647(1.7)$ & 1.00 & \\
\hline & Sub- total & $17,592(100.0)$ & $38,500(100.0)$ & & \\
\hline \multirow[t]{4}{*}{$>15$} & P.falciparum & $5983(75.0)$ & $12,057(68.1)$ & $1.61(1.39-1.87)$ & $<0.001$ \\
\hline & P.vivax & 1675 (21.9) & $5260(29.7)$ & $2.51(2.15-2.94)$ & $<0.001$ \\
\hline & Mixed & $319(3.1)$ & $398(2.2)$ & 1.00 & \\
\hline & Sub- total & 7977 (100.0) & $17,715(100.0)$ & & \\
\hline \multirow[t]{3}{*}{ Total } & P.falciparum & $23,274(69.7)$ & $57,023(69.0)$ & $2.66(2.46-2.89)$ & $<0.001$ \\
\hline & P.vivax & $8870(26.5)$ & $24,480(29.6)$ & $2.99(2.76-3.26)$ & $<0.001$ \\
\hline & Mixed & $1287(3.8)$ & $1184(1.4)$ & 1.00 & \\
\hline
\end{tabular}

Cl confidence interval, $O R$ Odds ratio; $<5$ and $<15$ indicated study subjects who were less than 5 and 15 years of ages in both sexes, respectively, $>15$ indicated those study subjects who were above 15 years of ages 


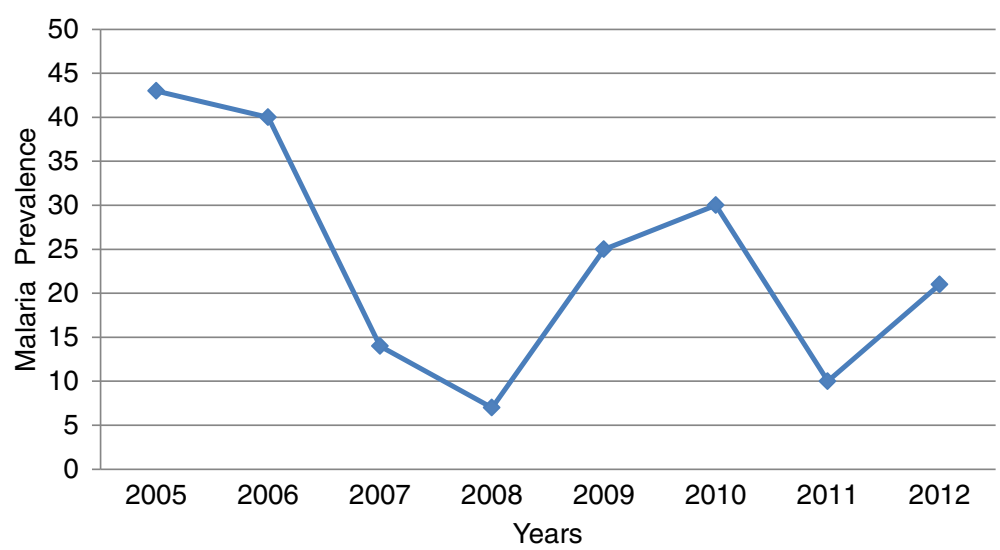

Fig. 1 Annual trend of malaria prevalence at Woreta town, Northwest Ethiopia (2005-2012)

\section{Discussion}

This study revealed individuals above 5 years of age were more affected than children below 5 years of age. This was in agreement with studies conducted in other parts of Ethiopia and South Africa [14, 15]. In contrast, higher prevalence of malaria was reported in children less than 5 years of age elsewhere in the country $[16,17]$. The observed lower prevalence of malaria in children under 5 years of age might be because of their less likely exposure to infected mosquito bite due to good awareness and practices of their parents/care takers on malaria control and prevention activities. In addition, the partially acquired immunity developed during childhood in such high malaria transmission area might have a protective role in this age group. In high malaria transmission settings, partial immunity to the disease is acquired during childhood. In such areas, the majority of malarial disease, and particularly severe disease with rapid progression to death, occurs in young children without acquired immunity [18].
The finding that males were more affected than females in this study was in agreement with that of other studies conducted in different parts of Ethiopia $[5,10,11]$. In contrast, lower malaria cases in males were reported from studies in Kenya [19] and Mozambique [20]. This might be explained by the fact that in the present study area males were often engaged in early night outdoor agricultural activities, hence, have got higher chance of exposure to be infected by the anopheles malaria vector. Evidences showed that much greater mosquito human-biting activities occurred outdoors than indoors and during early parts of the night, suggesting higher outdoor malaria transmission potential in Ethiopia [21].

$P$. falciparum malaria was the major cause of morbidity in the region. This was in agreement with a similar study conducted in Northwestern Ethiopia which reported that $P$. falciparum and $P$. vivax accounted for 75 and $25 \%$ of malaria morbidity, respectively [7]. The observed higher prevalence of falciparum malaria in the

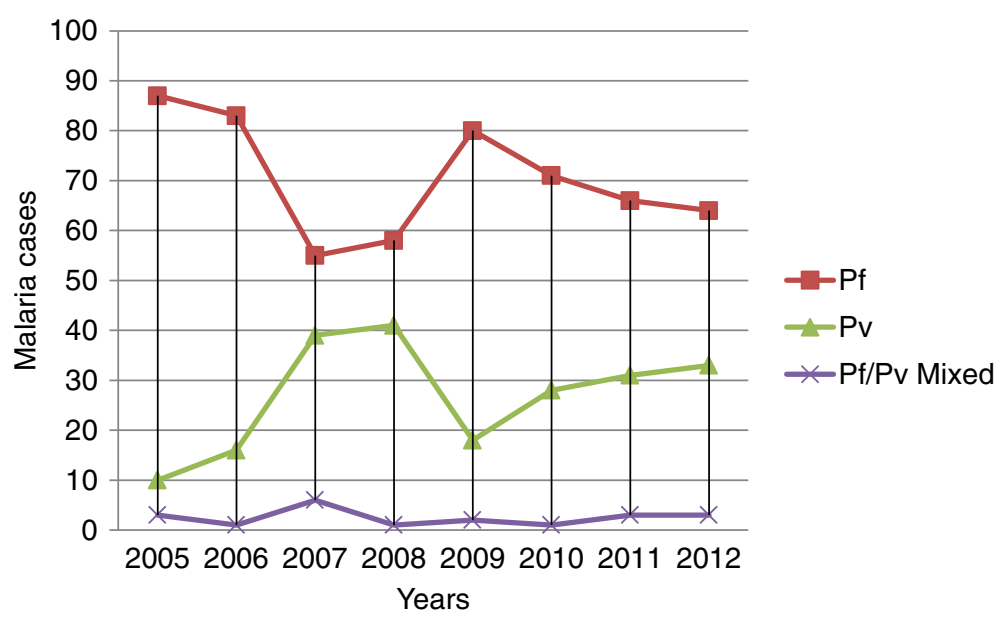

Fig. 2 Trend of malaria cases by year and malaria species at Woreta town, Northwest Ethiopia (2005-2012). Pf: Plasmodium falciparum, Pv: Plasmodium vivax, Pf/pv mixed: co- infection of Plasmodium falciparum and Plasmodium vivax 


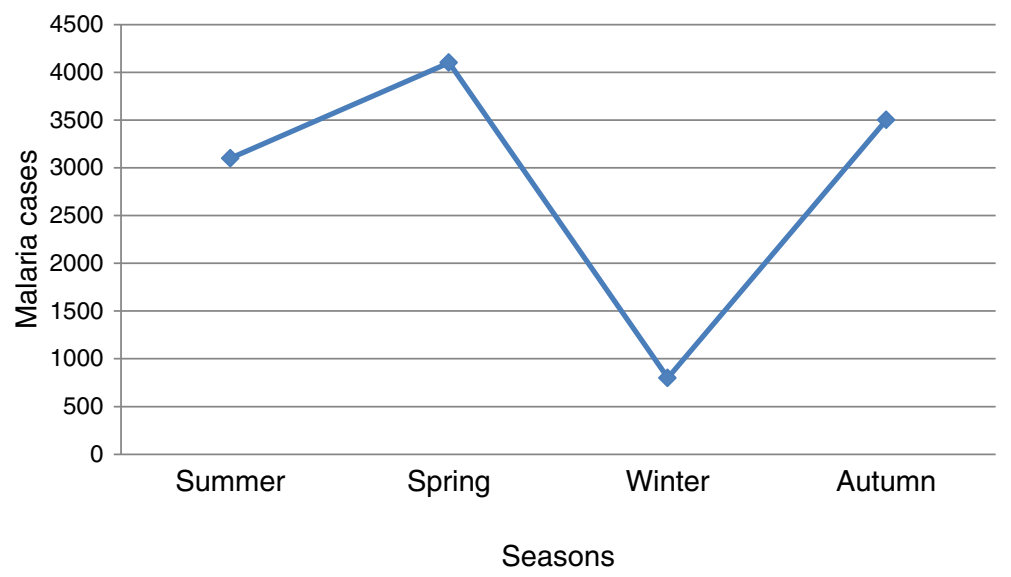

Fig. 3 An eight years (2005-2012) average seasonal distribution of malaria cases at Woreta town, Northwest Ethiopia

study area was consistent with the Ethiopian Federal Ministry of Health (FMoH) report [22]. However, higher prevalence of $P$. vivax malaria was reported in Southern Ethiopia [11-13]. Although it was difficult to reason out the above differences, it might be due to differences in topographic adaptations and intrinsic factors of the parasites.

In the present study, a proportional raise in the prevalence of $P$. vivax was recorded from the year 2009 to 2012. An increased rate of drug resistance has been reported in the study region. Therefore, chloroquine resistant vivax malaria may be responsible for the observed slight increment in the proportion of $P$. vivax in the last few years. This was in agreement with a similar study conducted in Southern Ethiopia [10]. In agreement with the present study, high peaks of malaria incidence were reported in the same years in a similar study conducted in Southwestern part of the country [11].

Despite the fluctuating trend, a general reduction of the high malaria prevalence, $47 \%$ in $2005,30 \%$ in 2010 and $21 \%$ in 2012 was recorded. This might be due to the continuous efforts made as part of the national malaria control program, which begun more than half a century ago [23]. This was in agreement with a study reported that since 2004, Ethiopia's health systems for case management and surveillance have been greatly strengthened [24]. In particular, in the Amhara region, an integrated malaria vector control measures were made based on the national malaria control strategies. The national malaria control strategies were guided by the Abuja (Nigeria) declaration which targeted to reduce the burden of malaria in at risk groups such as children and pregnant women for the year 2005 [25]. This general reduction of malaria prevalence coupled with the launching of the extensive malaria control strategies in 2005 [4] demonstrated the effectiveness of the control measures implemented during those specified periods (2005-2010) in the study area.
However, despite all these efforts, malaria persisted as one of the major health problems in Woreta town. A $28 \%$ average malaria cases for the years 2005-2012 and a $21 \%$ in 2012 was recorded, which was far higher than the regional (4.6\%) and the zonal (6.1\%) malaria prevalence [26]. This was in parallel with the report from the Ethiopian Malaria Indicator Survey [21] and a similar study conducted in the same study area (Tsegaye T: Assessment of the efficacy of arthemeter-lumefantrine $\left(\right.$ Coartem $\left.^{\circ}\right)$ for uncomplicated falciparum malaria at Woreta town, North Western Ethiopia, unpublished). In consistent to the findings of this study, similar works in other parts of East Africa revealed high prevalence of malaria in their respective study sites, $28 \%$ in Kenya and $38.1 \%$ in Tanzania [27, 28]. In contrary, a study conducted in southern Ethiopia reported a lower prevalence $(0.93 \%)$ of malaria [8]. The above difference in malaria prevalence might be explained by the fact that malaria distribution varied at varying geographical locations and altitudes.

\section{Conclusions}

A high prevalence of malaria was observed during the study period in Woreta town. A general reduction in malaria prevalence in the earlier years might have demonstrated the effectiveness of the malaria control program implemented in the area. However, in spite of integrated efforts made to control malaria and its vector, the disease persisted for more than half a century in the study area. Hence, more attention should be given in the practice and proper implementation of the malaria control activities in the local community. Further studies are needed to evaluate the independent effect of other possible special factors such as the ongoing massive rice irrigation activities in the study area, which might favor the reproduction of malaria mosquito vectors. 


\section{Limitation}

The present study was restricted to the health center recorded retrospective data and was unable to relate to the current prevalence status of malaria in the study area.

\section{Abbreviations}

$\mathrm{Cl}$ : Confidence interval; FMoH: Federal ministry of health; IRS: Indoor residual spraying; ITNs: Insecticide-treated mosquito nets; OR: Odds ratio;

SPSS: Statistical package for the social sciences

\section{Acknowledgements}

The authors are grateful to the Addis Ababa University, College of Natural Sciences for sponsoring this study. We would like also extend our deepest gratitude to Woreta health center working staff and administrators for providing malaria data and other relevant information for the development of this study.

\section{Funding}

All the financial support for the study's data collection, analyzing and writing up the research paper was obtained from the thematic research projects of Addis Ababa University, college of natural science with grant number GSR/ 2748/05

\section{Availability of data and materials}

All the datasets on which our conclusions relay on are presented in the main section of this manuscript.

\section{Authors' contributions}

AA: conceived the study, undertook the field works and statistical analysis, and made major contribution in drafting and writing the manuscript. ZT: made major contribution in the data analysis and writing up the study. BP: initiated the study and made major contribution in the study design, development as well as financial administrative issues. All authors read and approved the final version of the manuscript.

\section{Ethics approval and consent to participate}

Ethical clearance was obtained from Research Ethical Review Committee of Microbial Cellular and Molecular Biology Department, Addis Ababa University. The purpose and objective of the study was explained to administrative and health officials of the study area. Confidentiality issues of study participants were kept.

\section{Consent for publication}

Not applicable.

\section{Competing interests}

The authors declare that they have no any competing interests.

\section{Publisher's Note}

Springer Nature remains neutral with regard to jurisdictional claims in published maps and institutional affiliations.

\section{Author details}

${ }^{1}$ Department of Microbial, Cellular and Molecular Biology, Addis Ababa University, P.O.Box 1176, Addis Ababa, Ethiopia. ${ }^{2}$ Department of Biology, College of Computational and Natural Sciences, Debrebirhan University, Debrebirhan, Ethiopia. ${ }^{3}$ Aklilu Lemma Institute of Pathobiology, Addis Ababa University, P.O. Box 1176, Addis Ababa, Ethiopia.

\section{Received: 27 February 2018 Accepted: 27 July 2018}

\section{Published online: 08 August 2018}

\section{References}

1. WHO. Methods for surveillance of antimalarial drug efficacy. World Health Organization. Geneva, Switzerland. 2009. Available at: http://www.who.int/ malaria/publications/. Accessed 14 Oct 2014

2. WHO. World Malaria Report 2015, Summary. World Health Organization. Geneva, Switzerland 2016.

3. MOP. Malaria Operational Plan Ethiopia 2012. President's malaria initiative. 2015. pp.55-68. https://www.pmi.gov/docs/default-source/default- document-library/malaria-operational-plans/fy-15/fy-2015-ethiopia-malariaoperational-plan.pdf?sfvrsn=3. Accessed 9 Jan 2016.

4. $\mathrm{FMoH}$. Health and Health Related Indicators report. Federal Ministry of Health, Addis Ababa, Ethiopia. 2010. Available at: https://www. dktethiopia.org/. Accessed 4 Dec 2014.

5. Alemu K, Worku A, Berhane Y. Malaria infection has spatial, temporal, and spatiotemporal heterogeneity in unstable malaria transmission areas in Northwest Ethiopia. PLoS One. 2013;8(11):e79966. https://doi.org/10.1371/ journal.pone.0079966.

6. The Carter Center. Summary Proceedings 4th Annual Malaria Control Program Review Ethiopia and Nigeria. The Carter Center, Atlanta, Georgia. 2013. https://www.cartercenter.org/. Accessed 23 Sept 2014.

7. Alemu A, Muluye D, Mihret M, Adugna M, Gebeyaw M. Ten year trend analysis of malaria prevalence in kola Diba, North Gondar, Northwest Ethiopia. Paras Vect. 2012:5:173.

8. Woyessa A, Deressa W, Ali A, Lindtjørn B. Prevalence of malaria infection in Butajira area, South-Central Ethiopia. Malar J. 2012;11:84.

9. Tesfaye S, Belyhun Y, Teklu T, Medhin G, Mengesha T, Petros B. Malaria pattern observed in the highland fringe of Butajira, Southern Ethiopia: a ten-year retrospective analysis from parasitological and metrological data. MWJ. 2012;3:5

10. Hailemariam M, Gebre S. Trend analysis of malaria prevalence in Arsi Negelle health center, Southern Ethiopia. J Inf Dis Immu. 2015;7(1):1-6.

11. Sena $L$, Deressa W, Ali A. Analysis of trend of malaria prevalence in SouthWest Ethiopia: a retrospective comparative study. Malar J. 2014;13:188

12. Yimer F, Animut A, Erko B, Mamo H. Past five-year trend, current prevalence and household knowledge, attitude and practice of malaria in Abeshge, South-Central Ethiopia. Malar J. 2015;14:230.

13. NWZMS. Rainfall and temperature records for Woreta station. North Western Zone Meteorological Services, Amhara region, Bahir Dar 2004. http://www.ethiomet.gov.et/. Accessed 16 Mar 2013.

14. Gerritsen A, Kruger P, Loeff S, Grobusch P. Malaria incidence in Limpopo Province, South Africa, 1998-2007. Malar J. 2008;7:162.

15. Woyessa A, Gebre-Michael T, Ali A, Kebede D. Malaria in Addis Ababa and its environs: assessment of magnitude and distribution. Ethiop J Health Dev. 2002;16:147-55.

16. Alemu A, Tsegaye W, Golassa L, Abebe G. Urban malaria and associated risk factors in Jimma town, Southwest Ethiopia. Malar J. 2011:10:173.

17. Wakgari D, Ahmed A, Damen H. Malaria related health seeking behavior and challenges for care providers in rural Ethiopia implications for control. J Biosoc Sci. 2008:40:1-21.

18. WHO, Global tuberculosis report 2017. Malaria in children under five. Updated 2018 http://www.who.int/malaria/areas/high_risk_groups/children/en/

19. Temu A, Coleman M, Abilio P, Kleinschmidt I. High prevalence of malaria in Zambezia, Mozambique: the protective effect of IRS versus increased risks due to pig-keeping and house construction. PLoS One. 2012;7:e31409. https://doi.org/10.1371/journal.pone.0031409.

20. Brooker S, Clarke S, Njagi K, Polack S, Mugo B, Estambale B, et al. Spatial clustering of malaria and associated risk factors during an epidemic in a highland area of Western Kenya. Tropical Med Int Health. 2004;9:757-66.

21. Kenea O, Balkew M, Tekie H, Gebre-Michael T, Deressa W, Loha E, et al. Human-biting activities of Anopheles species in south-central Ethiopia. Para Vect. 2016;9:527.

22. FMoH. Assessment of the therapeutic efficacy of antimalarial drugs in Ethiopia. Addis Ababa: Federal Ministry of Health, Malaria and Other VectorBorne Diseases Prevention and Control Team; 2004.

23. Ethiopia MIS. Ethiopia National Malaria Indicator Survey 2011. The Ethiopian Health and Nutrition Institute and Partners 2012. https://www.ephi.gov.et/. Accessed 9 Feb 2013.

24. MOP. President's Malaria Initiative Ethiopia, Malaria Operational Plan Fy 2016. https://www.pmi.gov/. Accessed 12 Nov. 2014

25. Negash K. Ethiopia roll back malaria consultative mission: essential actions to support the attainment of the Abuja targets. Ethiopia RBM Country Consultative Mission Final Report 2004

26. The Carter Center. Prevalence and Risk Factors for Malaria and Trachoma in Ethiopia. 2007. https://www.cartercenter.org/. Accessed 4 July 2013.

27. Jenkins R, Omollo R, Ongecha M, Sifuna P, Othieno C, Ongeri L, Kingora J, Ogutu B. Prevalence of malaria parasites in adults and its determinants in malaria endemic area of Kisumu County, Kenya. Malar J. 2015;14:263.

28. Kim MJ, Jung BK, Chai JY, Eom KS, Yong TS, Min DY, et al. High malaria prevalence among schoolchildren on Kome Island, Tanzania. Korean J parasitol. 2015;53(5):571-4. 